\title{
10 The Revitalization of Zhizhu Temple
}

\author{
Policies, Actors, Debates
}

Lui Tam

Maags, Christina \& Marina Svensson(eds), Chinese Heritage in the Making: Experiences, Negotiations and Contestations. Amsterdam: Amsterdam University Press, 2018

DOI $10.5117 / 9789462983694 / \mathrm{CH} 10$

\begin{abstract}
This chapter discusses a case of a heated public debate on heritage conservation that revealed a power asymmetry in heritage conservation among various actors. It focuses on the revitalization of the Zhizhu Temple in Beijing, which suffered from years of neglect since its secularization in 1949. A company leased the temple in 2007 and started renovating it, with the aim to turn it into an upmarket recreation venue and art gallery. The renovation earned a UNESCO Asia-Pacific Awards of Cultural Heritage Conservation in 2012. Criticism was, however, voiced over the fact that a former temple was being used as a 'private club'. The debate illustrates both complex and unclear regulations and different views among various actors on how to preserve and reuse heritage sites.
\end{abstract}

Keywords: revitalization, timber architectural heritage, temple, social debate, stakeholder, China

Making use of historic buildings has had a long history and has become one of the main issues in cultural heritage conservation worldwide, including in China. Regular maintenance is one of the most effective means of conservation and strongly relies on daily care. Therefore, a suitable function for historic buildings, which is in line with the visions and needs of responsible caretakers, is significant to the conservation and sustainable life of heritage sites. The functions of heritage buildings, however, alter over time owing to changes of ownership or users. In China, due to dramatic political and economic changes over the twentieth century, a lot of historic buildings have lost their original functions. When they are identified as 'heritage', their maintenance becomes a tricky issue. Incompatible or unsustainable 
use of heritage buildings can cause irreversible damage to their value. In China, this has become a pressing issue and resulted in heated debates. In the case of religious buildings, such as temples, the discussions have been particularly controversial. There are three main reasons for this: Firstly, the relative vulnerability of the structure; secondly, the emotional value attached to both the buildings and their original use; and, thirdly, controversial opinions on the reuse of religious buildings. The timber structure of traditional Chinese architecture is very delicate. In Chinese society, people usually have a strong emotional attachment to Buddhist religious buildings as they manifest the main religious belief in China. Furthermore, some people still have doubts about reusing a religious space for different non-religious functions. Nevertheless, there have been some attempts by different actors to recreate a sustainable life for religious heritage. But such attempts have also attracted criticism that touches upon issues of moral and appropriate use, techno-legal limits to reuse, and the private versus public dimension of reuse.

The recent case of the revitalization of a temple in Beijing and the resulting heated debate over appropriate reuse illustrate the complex issues at hand. Zhizhu Temple, now known as the Temple Restaurant/Hotel Beijing, is located in the historic centre of Beijing, less than 800 metres from the Forbidden City, a World Heritage Site. During the last century the temple was occupied by different organizations and factories and had decayed into a hollow deserted complex. Starting seven years ago, a company initiated a project to renovate and revitalize the complex. The renovation strategy was based on their idea of reusing the space as a high-end hotel, a restaurant, and an art gallery. The restoration and renovation project took five years and was awarded the UNESCO Asia-Pacific Awards of Cultural Heritage Conservation in 2012. However, such glory did not just win compliments for the team. In fact, the case has brought criticism from the public and official media. The discussion involves whether it is suitable to have a hotel and a restaurant in a temple, and whether this usage is legitimate. Official media has criticized the use of the former temple as a 'private club' while not providing an accurate definition of 'private club'. The issue is complicated further by the government's efforts to revise heritage law and change heritage revitalization policies.

This chapter aims to discuss the debates on Zhizhu Temple and analyse the social, historical, and cultural backgrounds of these debates. The chapter also investigates the general legislation and policies concerning heritage revitalization and adaptive reuse, based on the analysis of the situation and different institutions involved. It intends to shed some light on the conflicts and discrepancies between the introduction and interpretation 
of international standards on revitalization in China. It thus also analyses the practice and implementation at the local level as well as the reactions and views among the general public.

\section{Legislative background}

Utilization has always been a means of keeping historic buildings alive. However, not all kinds of utilization are beneficial to the conservation, presentation, and interpretation of the values of heritage. The utilization of heritage is encouraged in China as a basic principle and regulated in national and regional legislation.

In China's national legislation, 'reasonable utilization' is among the four principles that compose the foundation of the legislation system for cultural heritage conservation (National People's Congress 2015: Art. 4). The national legislation emphasizes the social purpose of the use and strongly recommends that a heritage site be used as a museum, a preservation institute, or a tourist location. It also emphasizes that the 'original state' of the heritage site should be kept and the safety of the heritage buildings should not be undermined during utilization. The national law sets down the basic principles and restrictions for the utilization of heritage sites. However, the three suggested functions have limited the choice of reuse. For a lot of the heritage sites it is difficult to create enough revenue to maintain the site as a museum or a tourist attraction, for instance. On the other hand, if the owner or the user of a heritage site would like to explore other functions, the national law provides no guidelines to determine if it is a compatible use or not. It should be noted that even though the national law for heritage conservation has been amended several times up until 2015, the main body of the law has remained more or less the same since 2002 . Even as this chapter is being written, the national law for cultural heritage is going through yet another major revision which will inevitably give more weight to the reutilization of heritage. In the latest draft of the national law, the restrictions to the three functions have been deleted. More freedom is given to the utilization of the heritage sites and the regulations are more elaborate (Government of PRC 2016: Chapter 6).

Several municipalities have also established their own regulations for cultural heritage conservation. For example, the Regional Regulations of Cultural Heritage Management of Beijing (Beijing Municipality 1998: Art. 25) and the regulations for the conservation of historic districts and historic buildings of Shanghai (Shanghai Municipality 2002: Art. 4) and Qingdao 
(Qingdao Municipality 2012: Art. 3) emphasize 'reasonable utilization' according to the protection levels and categories of the heritage sites. In the more recent Qingdao regulation, it states explicitly that the development of tourism and related businesses that are compatible to historic buildings is certainly encouraged. In addition, it points out that in order to change the function of a historic building, the owners or the users should ask for the stakeholders' consent (Qingdao Municipality 2012: Art. 13). These regulations align with the national law and aim to provide more practical and detailed instructions for practices. They are more responsive to current issues but due to lack of research and guidelines, the content concerning utilization is still limited.

Besides legislation, standards and principles function as guidance to the practices in the field of conservation. In the most recent revision of the 'Principles for the Conservation of Heritage Sites in China', a whole chapter about appropriate use has been added. This has so far been the most detailed and specific principle on the matter in China. It defines 'appropriate use' in a Chinese context (ICOMOS China 2015: Art. 40 and commentary) and summarizes the criteria that an appropriate use should meet. They include the following elements: sustainability and public/community benefit. To be sustainable, an appropriate use should be within the heritage sites' capacity limits, without changing its character-defining elements. More importantly, an appropriate use should be an added value and an important means to conserve a heritage site and maintain its vitality. Furthermore, it specifically talks about two situations: retaining historic functions (ICOMOS China 2015: Art. 44) and adaptive reuse. For those that have lost their original functions, adaptive reuse is a means to help sustain the heritage. It points out that the assessment of its value and its current state prior to the determining of a new use for the site is very important. In addition, a selection of options should be proposed and compared. The adaptation should not undermine its value or character defining elements, and should be reversible (ICOMOS China 2015: Art. 45).

In China, policies in addition to laws and regulations have a great impact on the practices of cultural heritage conservation. Since 2011, revitalization ${ }^{1}$

1 There is currently no universal definition of 'revitalization' in international documents concerning architectural heritage conservation. However, this definition is used globally across different continents with essentially similar meanings. Sometimes the similar process is described as 'rehabilitation' (Canada's Historic Places 2010: 16) or 'adaptive reuse' (ICOMOS China 2015: 83). A senior secondary curriculum material created by the Hong Kong Institute of Architects and the University of Hong Kong defines revitalization as: 'To conserve existing (sometimes historic) buildings or districts by putting them to good contemporary use. This 
and utilization have frequently appeared in the policies and strategies that concern cultural heritage conservation. In 2011, a Temporary Management Regulation of Profitable Activities of State-Owned Protected Cultural Heritage Sites was put forward. The regulations are only applicable to the state-owned sites that are used as museums, conservation research institutes, or tourist sites (State Administration of Cultural Heritage 2011: Art. 2). It states that it is encouraged to operate profitable activities on such sites, but the activities should be compatible with the heritage sites and should be of public service. They should also be compatible with the cultural attributes of the heritage sites. The State Administration of Cultural Heritage (SACH) has held conferences in 2013 on the topic, seeking to share experiences between the mainland, Hong Kong, Macau, and Taiwan. Increasing the diversity of uses and involving private funds and organizations in the revitalization process are supported, but the public nature of the use is still emphasized. It seemed that, thanks to the shift in official attitude, the revitalization and utilization of heritage sites was on a promising path. However, this was followed by the announcement of a Temporary Regulation about Forbidding Private Clubs in Public Resources of Historic Buildings and Parks in 2014 (hereafter referred to as 'Temporary Regulation') (Ministry of Housing and Urban-Rural Development 2014: Art. 1 and 2). Before this regulation, even though it was not specifically defined, private clubs were believed to be entertainment venues that were open to a selected few. However, in the Temporary Regulation, 'private club' is given a rather broad meaning: high-end catering venues, recreation venues, gyms, beauty salons, entertainment venues, accommodation, and reception venues, etc. (Ministry of Housing and Urban-Rural Development 2014: Art. 1 and 2). Compared to the earlier policy of increasing diversity, this Temporary Regulation condemns inappropriate uses while simultaneously using the notion of 'private club' to cover a lot of entertainment-related uses which are not necessarily inappropriate when well restricted and designed. Upon the implementation of this Temporary Regulation, a lot of these kinds of venues were ordered to close down. On the one hand, this meant that some of the heritage sites were able to obtain a second chance, but on the other hand, some of the sites became vacant and lacked caretakers once again.

approach gives historic buildings and districts a 'second life' by reconnecting them with society' (Faculty of Architecture, the University of Hong Kong 2012: 7). Considering that Hong Kong is one of the pioneers to promote revitalization of historic buildings in the greater China region and much exchange of experience has taken place between mainland China and Hong Kong in recent years, this definition is applicable under the context of this article. 


\section{History of revitalization in China}

The reuse of old buildings had taken place long before it was considered a question of revitalization. During the first few decades of the PRC very few new buildings were constructed due to the lack of financial resources, so many factories, institutes, governmental departments, and schools simply moved into a lot of existing temples and imperial residences. The previous uses of these complexes were changed and their original functions interrupted. Such changes happened not just in big historic cities like Beijing, but also in small and remote villages. During the occupation, because of the lack of awareness, supervision, and analysis of the values of heritage sites, a lot of occupants built new buildings within the courtyards. To adjust to the new standards of modern life and comfort, modern infrastructure such as ceilings and floors were added. These changes drastically altered the original layout and structures of the heritage sites, and some of them are not reversible. Certain changes diminished the values and affected the authenticity and integrity of the sites. Yet, some of the traces left by such occupation, for instance, slogans from the Cultural Revolution and the 'Great Leap Forward', are evidence of the multiple layers of reuse over time and are now part of the buildings' history.

In the last few decades, a lot of these organizations and factories underwent major changes. Many of them closed down or moved out of the buildings, leaving more and more traditional architectural complexes empty. There are usually two options available to these complexes - to regain their original function or to seek new ones. In the 1980s, a shift in religious policy meant that many religious buildings were returned to religious groups. In rural areas most of them became temples again. Yet, this option is not possible for all religious sites. As the religious population in the urban environment has dwindled significantly, many temples in cities have not become temples again.

When the notion of revitalization was first introduced in China in the 1990s, it mainly focused on modern heritage, such as industrial heritage and colonial heritage. A lot of state-owned factories closed down after the market reforms, leaving gigantic factory buildings vacant. Starting in Shanghai and Beijing, these huge spaces first attracted the attention of contemporary artists and many colonial buildings were also turned into art galleries or cafés (Zhuang 2004). These new functions were considered quite compatible with the heritage buildings. However, this issue becomes more complicated when it concerns Chinese traditional architecture, especially religious buildings. Some of the complications of reuse are related to the 
nature of the heritage sites. Chinese traditional architecture is mainly made of timber, is very vulnerable to fire, and requires more frequent and careful maintenance. This limits the range of suitable use. In addition, as Chinese architecture usually consists of many small buildings and open courtyards, it is not so easy to make adaptations without undermining the historic fabric of the sites. Further challenges are related to the matter of management, as most of these sites have a very complex property rights and ownership situation. They may be owned or managed by several organizations, and each of them might have different ideas about the site's future. Moreover, it requires more money and care to revitalize a heritage building than to construct a new building. Without financial or policy support, companies that seek profits in reusing heritage may easily ignore public benefits, while non-profit organizations would find it difficult to operate sustainable functions. Currently, heritage sites that are revitalized as tourist locations or museums are mostly funded or supported by the state. Most other business models either exploit the heritage sites or are not sustainable enough to last. Many heritage buildings are therefore vacant. Once the above-mentioned Temporary Regulation is implemented, it is not hard to believe that even more buildings will be in need of new compatible functions.

\section{Zhizhu Temple: History and the revitalization process}

This case study demonstrates the situation in more depth. Zhizhu Temple is one of the many heritage sites that have experienced dramatic changes throughout its history. The recent revitalization of Zhizhu Temple in Beijing has brought many of the issues discussed above into the open, and it helps us understand the challenges of reusing religious heritage sites in the context of China and the conflicts between legislation, policies and practices.

On the site of today's Beijing Municipally Protected Heritage Site 'Songzhu Temple and Zhizhu Temple' lies the main complex of the two imperially built temples from the Qing dynasty. They are located in the centre of historic Beijing. During the Qing dynasty, before Zhizhu Temple was built, Songzhu Temple was already a very important Tibetan Buddhist temple, as it was the temple where Cangkya Khutukhtu III resided in when the Yongzheng Emperor sent for him from Qinghai to Beijing. ${ }^{2}$ Cangkya Khutukhtu III spent ten years studying and accompanying the son of the Yongzheng Emperor, who later became the mighty Qianlong Emperor. The 
Buddhist monk was one of the most important political figures of his time. Next to Songzhu Temple, there was the Ming Dynasty Sutra Printing Factory (Fanjing Chang). In 1734, Songzhu Temple and the Ming Dynasty Sutra Printing Factory (Fanjing Chang) were renovated. The newly restored and extended Fanjing Chang was later renamed as Fayuan Temple and became the affiliated temple of Songzhu Temple (Cui 2013: 76). In The Complete Map of the Capital, drawn in $175^{\circ}$ (the fifteenth year of the Qianlong Emperor's reign), there were only some residential courtyards on the site where Zhizhu Temple now stands (Haiwang and Castiglione 1750). In a Zouzhe ${ }^{3}$ submitted by Lord Heshuo Zhuang in $175^{6}$ (the twenty-first year of the Qianlong Emperor's reign), he reported the reconstruction and restoration of the complex (Zou Xiao Dang 1756). This valuable text recorded the alteration of the original complex of Fanjing Chang (Fayuan Temple) and also the building of a new temple on the site of some Manchurian residences. The Zouzhe requested the Qianlong Emperor to write the plaque for the temple's title. This new temple, as we see today, is Zhizhu Temple. The three temples, Songzhu Temple, Fayuan Temple, and Zhizhu Temple, stood side by side, representing one of the most important religious complexes in the capital.

Not many written records from the imperial archive can be found concerning the evolution of Zhizhu Temple. However, as shown in historic maps, it can be assumed that the scale and layout of the temple remained more or less the same until the early twentieth century (German East Asian Expeditionary Corps 1907). The temple is also occasionally mentioned as the venue of some activities of the imperial family during the second half of the Qing dynasty. Its function as a temple remained until the founding of the People's Republic of China in 1949. From the 1950s, just like in the case of a lot of temples and large residential complexes around the country, several factories and organizations took residence in the tri-temple complex. The first new resident in Zhizhu Temple was the Gold Lacquer Mosaic Factory, followed by a bike factory, the Jingshan Binding Factory, and the Jingshan Medical Facilities Factory. They occupied most of Zhizhu Temple. Meanwhile, the last two courtyards to the north of Jingshen Hall (the back hall) were occupied by Beijing Interior Design Institute. In the 1970s, Beijing Dongfeng TV Factory was established, which produced bestselling black and white TVs during that time. This big company occupied most of the buildings of Songzhu Temple and Fayuan Temple, replacing the former two factories. In 1974, the TV factory demolished the gate, the Drum and

3 Zouzhe is the correspondence between the officials and the emperors to discuss about all kinds of issues. 
Figure 10.1 An overview of Zhizhu Temple

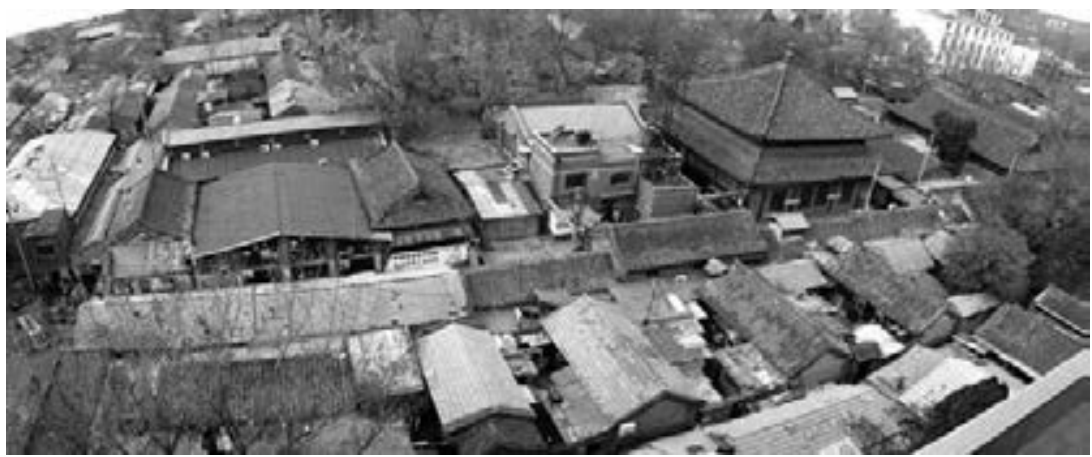

Photograph by Jinze Cui

Bell Towers, the Hall of the Heavenly Kings of Songzhu Temple, and almost all the buildings of Fayuan Temple. Later, the Dongfeng TV Factory also occupied the front hall and the west side hall of Zhizhu Temple (Cui 2015). Fortunately, most of Zhizhu Temple was spared during this disastrous demolition.

In 1984, the remaining Songzhu Temple and Zhizhu Temple were identified as Beijing's Municipally Protected Heritage Site. Due to the policy of ensuring the property rights of religious organizations, the property rights of Zhizhu Temple and Songzhu Temple were rightfully handed to the Beijing Buddhist Association, with the Dongfeng TV Factory still retaining the right to use the complex. In September 1992, Dongfeng TV Factory was annexed by a state-owned enterprise - the Mudan (Peony) Group. The factory was moved, leaving Beijing Peony Four Star Audiovisual Company on the site of Zhizhu Temple. A small hotel was established in the complex. During this period of reuse, the temple was not well cared for or maintained (Cui 2013: 78-80).

Today, Zhizhu Temple is a sophisticated high-end catering and accommodation venue as well as a cultural and art space. It contains a boutique hotel, an upmarket restaurant called TRB (Temple Restaurant Beijing), a gallery space, and some other areas for cultural events. In 2005, when Belgian banker Juan van Wassenhove, one of the founders of the Temple Republic, first encountered Zhizhu Temple, it was just a hollow, deserted complex closed to the general public. After about a decade of neglect and lack of maintenance, the original structures of Zhizhu Temple had fallen in decay and bore heavy traces of inappropriate adaptations. The courtyard was crowded with one- or two-storey buildings added during the factory 
period. But at the same time, Van Wassenhove was amazed at the beauty of the accumulated layers of the temple's 250-year history. In 2007, Van Wassenhove and his business partners Lin Fan and Lixian Chow, who were in the film industry, started the revitalization of Zhizhu Temple. A master plan to guide the whole process of the revitalization was created by the founders. It contained two intertwined phases: The restoration and adaptive reuse of the heritage site. A few months later, the team managed to sign a 21-year lease with the Beijing Buddhist Association, which manages the property of Zhizhu Temple, and the Mudan Group, who has the right to use the site for several decades. The lease allows Dong Jing Yuan, the Beijing subsidiary of the Temple Republic, to restore part of Zhizhu Temple. It also gives them the right to use and manage the operation of the site. The utilization includes using the site as a hotel, a restaurant, and for other cultural and promotional events. After acquiring the approval from the Beijing Municipal Bureau of Cultural Heritage, the team started the fiveyear-long restoration of the temple.

The restoration salvaged the temple's original structures, especially the Dugang Hall (the main hall), which suffered a major fire in the 1960 os. The blaze charred almost half of its main structure. The restoration plan had to be adapted to replace some of the timber components in order to stabilize the structure. The team also tried to preserve most of the original doors, windows, as well as the Qing dynasty frescoes on the buildings. A Chinese traditional art specialist was invited to use the mounting techniques employed in the restoration of Chinese traditional paintings to restore the Sanskrit paintings from the 180 ceiling boards in the main hall. Other original frescoes were also left in place after being cleaned and stabilized, preserving the original material from hundreds of years ago, as well as the historic traces left by time. The plan of the renovation, besides complying with the basic principles of conservation, also took into account the future usage of the heritage site. For instance, floor heating and double-glazed inner windows and doors were added so as to meet the criteria of modern comfort as well as to retain the original facade of the buildings. In order to preserve and present all the layers of history, traces from the later periods of the temple are also preserved. After demolishing several dilapidated extensions that were also interfering with the preservation and presentation of the temple, some of the added buildings from the factory period were maintained and adapted into a restaurant, a hotel, and a conference venue. Slogans from the Cultural Revolution period were preserved in the main hall, telling the story of the temple's dramatic ups and downs. 
After the restoration, the venue opened to the public in 2011. In 2012, the restoration project of Zhizhu Temple was awarded the UNESCO Asia-Pacific Awards of Cultural Heritage Conservation. The award aims to recognize and encourage private efforts and public-private initiatives in successfully restoring structures of heritage value in the region. The restoration project of Zhizhu Temple was the only project from China and the only privately funded project among the 43 projects of that year. The award praised the comprehensive restoration work the team had accomplished and the team's determination to respect the authenticity of the various dimensions of historical and architectural significance. It also applauded the fact the restoration of the temple had 'enabled the rich layers of its history to be revealed, enhanced and celebrated' and the heritage site had been 'restored, interpreted and returned once again to the public with a new function as a venue for cultural events and activities' (UNESCO 2012).

Today, the venue is a complex with multiple functions. The south of the complex is for public functions, the east side is designed to hold conferences and art exhibitions, the west part comprises hotel rooms, and the north side of the complex is for more private use. The historic buildings in the complex include (from south to north) the gate, the Hall of Heavenly King, two side halls, the Dugang Hall (the main hall), and some side rooms that used to be the monks' residence. Now the ancient gate is used as the entrance to the complex and a small exhibition area, displaying a short documentary and a digital gallery of the restoration project of the temple, as well as some art objects. The Hall of Heavenly King, connected to a factory building on the west side, is used as the reception area of the restaurant, whilst the factory building was adapted into the main dining area. The kitchen and other infrastructures are also located in the factory buildings. Across from the dining area, another building from the factory era is now used as the main art exhibition space. Both the facades of these two side buildings were adapted with traditional Chinese elements so as to make them compatible with the historic buildings and environment in the first unit of the complex. Between the Hall of Heavenly King and the Dugang Hall, there is a two-storey factory building. One has to admit that it seems rather extreme to preserve this building since it blocks almost half of the view to the front facade of the main hall from the central axis. It reflects a different understanding of the values of heritage and the way of continuing its cultural significance: The two-storey building, which now holds several suites of the boutique hotel, offers a close-up view of the main structure - the bracket sets that support the roof are significant components of the facade of Chinese traditional buildings. This view, although fairly limited to 
the hotel's customers, would not exist if the two-storey building had been demolished. The sidewall of this factory building is now a screen for open-air projection. During the evening, when there is no activity, the shadow of a tree growing next to it is projected onto the whitewashed wall, creating a tranquil and artistic atmosphere in the courtyard. The Dugang Hall, being the most spacious area in the complex, is reserved for conferences or activities of a larger scale. Despite its outstanding size, which attracts people's attention, the Dugang Hall is no longer the most frequently used space in the whole complex. The focus of the usage has changed. This inevitably shifted people's understanding of the complex in a way that would never have been the case if the complex were still used as a religious space. But it also reduces the frequency of usage and disturbance of the most important historic structure in the temple. Behind the Dugang Hall, there is another factory building that has also been adapted into a conference space, whereas the side halls and side rooms are used as the hotel reception, smaller dining halls, and small hotel rooms.

The neighbouring Songzhu Temple, however, has a very different story. A corporation called Songzhu Famous Courtyard now occupies the remains of Songzhu Temple and the last unit of Zhizhu Temple behind the Dugang Hall. The venue is completely closed to the public and is used as a luxurious private club. During its adaptation, a few historic buildings were torn down or disrespectfully modified for the new function. The newly repainted Jingshen Hall of Zhizhu Temple, now seen over the wall that cuts through the temple and separates the two venues, creates an obvious contrast to the timeworn counterparts on the other side of the wall. During the restoration of Zhizhu Temple, a beautifully carved stone base was unearthed during the search for the original ground level of the temple. It belongs to the moon platform ${ }^{4}$ of Jingshen Hall on the other side of the wall. Even though Dong Jing Yuan does not use the building, the team altered the restoration plan so as to preserve the historic remnant.

For almost a year after the temple's low-profile opening, only a limited number of people had actually been inside the temple, partly because only the wing of the restaurant was open and the price range is somewhat above average. But since receiving the UNESCO Asia-Pacific award and the opening of the hotel wing and art gallery, the temple has seen an increase in the number of visitors. The venue is now not only an important heritage attraction, but also a tasteful space for cultural events and art exhibitions,

4 A moon platform is a platform space in front of the hall, extended from the base of the building. 
Figure 10.2 Zhizhu Temple after revitalization

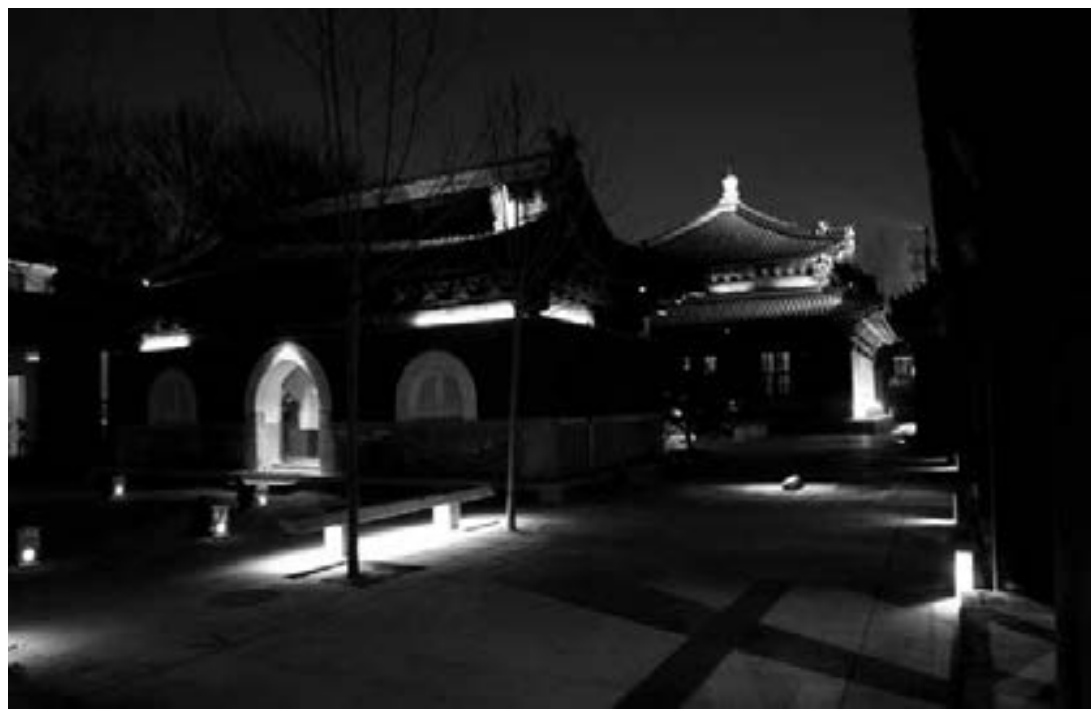

Photograph by Lui Tam

including the only James Turrell light art installation in China. Up until recently, the main complex and the art exhibitions have been open to the public for free during the restaurant's opening hours. The number of customers can reach up to more than 4000 a week. In addition, there are visitors who just wander into the complex. Most of the visitors enjoy the historic beauty that was re-established by the restoration and the serene atmosphere of the complex despite the hustle and bustle in the centre of the capital. ${ }^{5}$

\section{Debates and critical voices: What should heritage be used for?}

However, the revitalization of Zhizhu Temple did not just bring the team compliments. Even before the temple was reopened in 2011, there were already critical voices. The notion of revitalization is still very new to China. Whenever a site is reused as a profitable space, it draws attention from conservationists and the public. This is especially the case for the revitalization of a former Buddhist temple and a heritage site. Hence, when it became common knowledge that the temple was going to be a high-end 
Western restaurant, doubts and criticism flooded the Internet. According to the initiators, the team was very discreet about getting media attention for the UNESCO award due to the fear that it might cause a negative effect. Nevertheless, as increasing attention was brought to the site, the public opinion started to vary and the public debates became more and more heated. Some made positive comments on the restoration project and reckoned that the revitalization was based on a respectful organization of the heritage site, whilst some others opposed the idea of reusing a religious space as an entertainment and catering venue.

The discussion went viral when the state media criticized the project for using the temple as a 'private club' (Li et al. 2014). In the report, 'private club' referred to the notion mentioned in the Temporary Regulation, but for the majority of the public, the definition is still rather unclear. The news is also clearly confusing the Temple Hotel with the Songzhu Famous Courtyard. The way the article describes the functions of these two venues and the activities that occur in them is very misleading. People that have never been to the two complexes would not be able to tell that these are two completely separate venues. The information given in the news about the Temple Hotel also appears to be less than thorough since nothing about the restoration project and the UNESCO award is mentioned. It is, however, understandable as there are many negative precedents in similar situations. Heated discussions also began on social media. The immediate response from most of the readers was to criticize both of the venues, but there are also other readers who know more about the actual situation and try to clarify it, some of who are in the conservation or related fields. The discussion has also extended to whether it is justified to use religious temples as catering venues. An argument written by one sociologist in the conservation field titled 'Why Couldn't Zhizhu Temple Be a High-end Restaurant?' is widely believed to be one of the most well-known arguments against the state report (Yan 2014). It should be noted that this article was intended to be posted in the official media. However, it did not pass media control because of its controversial views. After the news report by the Xinhua Press, several influential media outlets tried to conduct more extensive research and provide more objective reports (Zhang 2015). The situation became quite confusing for the public since different reports told various versions and provided sometimes contradictory stories. In January 2015, another news report from Phoenix Press claimed that the 'private clubs' in the complexes have closed down while copying the misleading information reported in the previous accounts. 
The departments for cultural heritage are also among the actors steering the direction of the discussions. The State Administration of Cultural Heritage (SACH) kept silent in the beginning. In fact, it never gave a clear statement on the subject and it also never tried to clarify the situation. Only when more information was made public did SACH show its support for the Zhizhu Temple's restoration achievement, albeit in a very discreet way. In contrast, the Beijing Municipal Bureau of Cultural Heritage, which is the supervisory department responsible for the protected site, has allegedly been trying to close down both venues. The different attitudes among the departments show that the public discussion had put a lot of pressure on them.

In response to the extensive discussions and confusing coverage in the media, an MA student from Tsinghua University, Mingxia Zhu, carried out a small online survey to better understand the situation and people's actual opinions (Zhu 2016). ${ }^{6}$ Over 200 samples were collected during the one-week survey. The age of those surveyed covers the range between 18 and 65 . About $5^{2}$ per cent of them had no background related to cultural heritage work. Even though it was a small survey, its results still reveal a variety of opinions on the issue. The survey shows that more than half of those surveyed have read about related reports on the issue, but a lot of them are not sure about the definition of 'private club'. To their knowledge, a 'private club' means a place where the public normally cannot visit. Despite that, about 80 per cent of those surveyed think the reports in the official media on the situation are not accurate or convincing enough. People tend to have strong opinions against using a temple as a private club, but when asked for opinions on using the non-historic buildings in the complex, more people think it is acceptable. The result is similar when 'private club' in the questions is replaced with 'restaurants'. In fact, more than half of the people surveyed think it is acceptable to use non-historic buildings in the heritage site as restaurants. And more than go per cent of them think that it is acceptable or should be encouraged to use heritage sites as profitable venues on condition that the conservation of the heritage sites is guaranteed.

It should be noted that a lot of people who hold very strong opinions against reusing a heritage site or a temple as profitable venues have never been to Zhizhu Temple, or do not know that Zhizhu Temple is open to the public. These opinions are held by people with professional background in conservation and heritage work as well as those without such expertise. Even when those surveyed were told that the exhibition area is free and open to the public, about 9 per cent of people still do not believe it is true. Over $5^{\circ}$ per

6 All statistics are credited to Mingxia Zhu. 
cent of those surveyed do not know much about the restoration projects of the temple, let alone the fact that the restoration project won the UNESCO award. The reasons why people have never been to the temple or are not planning to go to the temple are mostly that the price range is beyond their capacity or that they reckon a temple should not be used as an entertainment venue. The sophisticated atmosphere and the high price range create a certain mental obstacle for a lot of people. Among the opposing comments, Buddhist believers state that profitable activities stain the purity of a Buddhist temple. And some think that a high-end restaurant in a heritage site diminishes its public attributes. Those who hold neutral opinions tend to think that reasonable utilization is positive for the conservation of the heritage sites, but they also state that supervision and regulation are necessary, and a more accessible function could be beneficial. Nevertheless, over 9o per cent of those who have visited Zhizhu Temple give very positive comments of their impressions of the site. They appreciate and are impressed by the effort of the restoration as well as the artistic and cultural atmosphere created in the complex.

In the survey, people are also asked to choose which kinds of functions they think are suitable for the revitalization of heritage sites. Functions with public attributes are usually people's first choices. Museums and libraries are the top two options. As for profitable venues, culture-related functions such as bookstores are most welcome. People tended to choose a function that is open to the public over one that is not - among other suggestions mentioned there are community centres and performance spaces. The cultural and public attributes of the heritage sites are clearly valued.

As shown in this case, several factors contribute to such heated debates on various levels across the spectrum of the society. There was a clear miscommunication between the public sector, the private sector, the media and the general public due to the lack of transparency and accurate information. The information received by the public was distorted by incomplete news reporting, while the different views among the authorities on various administrative levels also contributed to the unclear situation. The various stakeholders in addition had different interpretations of what a positive revitalization of a religious heritage site would look like.

\section{Urban heritage and the challenges of revitalization}

The Zhizhu Temple case illustrates the challenges facing revitalization of traditional architectural heritage in China today. The lack of a clear legislative framework coupled with a complex ownership structure as well 
as the lack of stakeholder involvement and effective information channels are among the central factors that lead to conflicts and difficulties.

The complexity of the property rights of heritage sites in the urban environment remains one of the biggest obstacles preventing sites from obtaining a new lease of life. In practice, the property owners sometimes do not have the power or the will to ensure the conservation of the heritage sites, whereas the private sector, which is willing to help, does not have the access to subsidies or professional support. There are still very few people in the private sector that are capable and willing enough to carry out revitalization projects. Without the financial support from the government, the task of restoring and adapting heritage sites for compatible uses requires a lot of commitment.

In the case of Zhizhu Temple, the supposed caretaker of the heritage site - the Buddhist Association - did not carry out its responsibility to conserve the temple as it is stated in the national law. The Temple Hotel, the private sector company that conducted the conservation, did not get the official acknowledgement and support needed because of a lack of management mechanism concerning revitalization. This is especially true concerning the attitude of SACH. Even if the administration wanted to support the projects, the lack of related legislation has tied their hands. It is important to understand that state resources can no longer sustain all of the heritage sites that are pending revitalization. However, private actors need guidance in the maintenance and management of heritage sites.

According to international and Chinese standards for conservation, during the revitalization process, conservation of the heritage sites is essential and not to be compromised. Reasonable utilization should not only results in no harm but also add actual value to the heritage site. To be specific, a good revitalization project usually includes effective restoration or maintenance of the heritage sites and avoids inappropriate adaptation that would damage the significant fabrics and features of the site. It is also beneficial and sustainable to respect and continue the cultural significance of a heritage site (Australia ICOMOS 2013:3-4, 6-8; ICOMOS China 2015:50).

In the case of heritage buildings that are no longer used for their original purposes, their cultural significance can be continued by preserving the historic layers. If a new use is necessary, the adaptation may not undermine the elements that reflect its cultural significance, but rather preserve and present them for visitors. Sustainability also means that the new use is supposed to bring vitality to the heritage site so that cultural significance can develop organically. Where possible, functions that have connections with the site's historic and spiritual associations should be considered (Canada's Historic Places 2010: 16). 
This is especially important when it comes to traditional religious heritage buildings. Even though the criticism towards reusing temples neglects the fact that many of the temples have long lost their functions, the case of Zhizhu Temple nevertheless shows that the emotional attachment to temples is still deeply rooted in Chinese society. Zhizhu Temple has not been used as a temple for over half a century even though the Buddhist Association is now the managing department. One has to admit that the functions of a restaurant and hotel do not have a direct connection with the temple's religious history, but the revitalization project did bring vitality to the complex, and by organizing art and cultural events it has helped develop the site's cultural significance. The tranquil atmosphere of Zhizhu Temple has been well maintained and visitors are able to enjoy the historic enchantment of the temple. The complex is freely accessible to the public during the opening hours of the restaurant. The local community, on the other hand, has not been involved much so far, but without the support from the government, involving the community is very difficult for the private sector.

The revitalization of heritage sites has attracted a lot of public attention in recent years (compare also the chapters by Grazer Bideau and Yan and Cui in this volume). Public debates help bring different opinions to the heritage debate and work. The discussion on the Zhizhu Temple was influenced by unclear and contradictory media coverage. This reveals both the lack of a common understanding of the basic concepts underlying heritage conservation as well as the growing interest in heritage issues among broader segments of Chinese society (see also Svensson and Maags). Public participation in the decision-making process has proved to be quite challenging. The proposals for revitalization projects are usually not a result of open competition and it is not compulsory or recommended to acquire public opinions during the decision-making process. This is one of the reasons why the Zhizhu Temple became such a heated and controversial case. The public had no in-depth knowledge of the project and its main features, nor did they have a chance to express their opinions before the project had been completed. Hence, speculation and feelings of powerlessness were some of the reasons behind the critique of Zhizhu Temple. The Songzhu Temple, in contrast, escaped criticism because of the lack of media attention and public interest. Information and education on heritage issues as well as channels for public involvement are vital for gaining grassroots support from the public.

The challenges of restoring historic buildings are recognized by both the government and other actors today. The media has played an 
important and yet controversial role in this process. It has, on the one hand, raised public awareness on the topic, but, on the other hand, has sometimes led to confusion and conflicts due to misleading coverage. This is exactly what happened in the case of the Zhizhu Temple. The revitalization of the temple can be considered as a positive case because it brought significant improvements to the site. The project may also serve as an inspiration for innovative revitalization at similar heritage sites in China. However, it also revealed the complex relationship between different stakeholders and that if not based on correct information, public debates may lead to misunderstandings and conflicts. This study thus argues the importance of clearer legislative frameworks, conservation policies that support sustainable revitalization, coordination among different stakeholders, responsible and transparent information channels, and closer involvement of the general public, for successful revitalization projects.

\section{References}

Beijing Municipality (1998). 'Beijing Shi Wenwu Baohu Guanli Tiaoli' [Beijing cultural relics conservation regulations], 1998 Revision, http://law.npc.gov.cn/ FLFG/flfgByID.action?txtid=52\&flfgID=79228\&showDetailType=QW.

Canada's Historic Places (2010). 'Standards and Guidelines for the Conservation of Historic Places in Canada', http://www.historicplaces.ca/media/18072/81468parks-s+g-eng-web2.pdf.

Cui, Jinze (2013). 'Songzhu Si Ji Zhizhu Si - Sanshi Zaisheng Yuan' [The Three Temple's fate - Songzhu Temple and Zhizhu Temple], in Chinese Heritage, ed. by Rui Liu (Chinese National Geography), 70-88

Cui, Jinze (2015). 'Beijing Zhizhu Si Baohu Liyong Zhuangkuang Zai Diaocha' [Investigation on the conservation and utilization of Zhizhu Temple in Beijing]. China Culture Daily, 15 January.

Faculty of Architecture, the University of Hong Kong (2012). Hong Kong Today - Conservation \& Revitalization of Historic Buildings (Hong Kong: Hong Kong Institute of Architects).

German East Asian Expeditionary Corps (1907). 'Peking und Umgebung'. Archival map, United States Library of Congress, Geography \& Map Division.

Government of PRC (2016). 'Zhonghua Renmin Gongheguo Wenwu Baohu Fa Xiuding Cao'an' [Public consultation draft of the revision of the Cultural Relics Protection Law of the People's Republic of China], http://www.gov.cn/ xinwen/2015-12/28/content_5028604.htm. 
Haiwang, Shenyuan, and Giuseppe Castiglione (1750). 'Qianlong Jingcheng Quan Tu' [The complete map of the capital], http://dsr.nii.ac.jp/.

Australia ICOMOS (20131979). the Australia ICOMOS Charter for Places of Cultural Significance (The Burra Charter, revisions 1981, 1988, 1999, 2013) http://australia. icomos.org/publications/charters/

ICOMOS China (2015). 'Zhongguo Wenwu Guji Baohu Zhunze' [Principles for the conservation of heritage sites in China], ed. by Beijing Shi: Wenwu Chuban She (Beijing: Cultural Relic Press), http://hdl.handle.net/10020/gci_pubs/ china_principles_2015.

Li, Dexin, Jiaqi Zhan, and Yichen Yang (2014). 'Neibu Shehua Baixing Nanjin - Beijing Gugong Fujin De Siren “Simiao” Huisuo' [Luxurious inside and inaccessible to commoners: Private 'temple' clubs near Beijing's Forbidden City], Xinhua Net, 14 December, http://news.xinhuanet.com/politics/2014-12/14/c_1113636244.htm. Ministry of Housing and Urban-Rural Development (2014). 'Guanyu Yanjin Zai Lishi Jianzhu Gongyuan Deng Gonggong Ziyuan Zhong Sheli Siren Huisuo De Zanxing Guiding' [Temporary regulation about forbidding private clubs in public resources of historic buildings and parks], http://www.mohurd.gov.cn/ zcfg/jsbwj_o/jsbwjcsjs/201411/t20141128_21966o.html.

National People's Congress (2015). 'Zhonghua Renmin Gongheguo Wenwu Baohu Fa' [Cultural Relics Protection Law of the People's Republic of China], 2007 Revision (2015 Amendment), http://www.npc.gov.cn/wxzl/gongbao/2000-12/o6/ content_5004416.htm.

Qingdao Municipality (2012). 'Qingdao Shi Lishi Jianzhu Baohu Guanli Banfa' [Historic buildings conservation regulations of Qingdao], http://www.qingdao. gov.cn/n172/n24624151/n24626675/n24626689/n24626703/130914205551873020. html.

Shanghai Municipality (2002). 'Shanghai Shi Lishi Wenhua Fengmao Qu He Youxiu Lishi Jianzhu Baohu Tiaoli' [Historic districts and historic buildings conservation regulations of Shanghai], http://www.shanghai.gov.cn/nw2/nw2314/ nw3124/nw3177/nw3181/u6aw1126.html.

State Administration of Cultural Heritage (2011). 'Guoyou Wenwu Baohu Danwei Jingying Xing Huo dong Guanli Guiding' [Temporary management regulation of profitable activities of state-owned protected cultural heritage sites], http:// www.sach.gov.cn/art/2011/8/31/art_8_99874.html.

UNESCO (2012). 'Asia-Pacific Award Statement', http://www.unescobkk.org/ culture/heritage/awards/previous/2012/.

Yan, Haiming (2014). 'Zhizhu Si Pin Sha Buneng Kai Gaodang Canting?' [Why couldn't Zhizhu Temple be a high-end restaurant?], Douban, 19 December, http://www.douban.com/note/472529974/. 
Zhang, Fan (2015). 'Beijing Zhizhu Si Gaizao, Shi “Gaodang Huisuo” Haishi Wenwu Xiushan Dianfan?' [Adaptation of Beijing Zhizhu Temple, 'high-end club' or model of heritage restoration?), The Paper, 22 January, http://www.thepaper. cn/newsDetail_forward_1296216.

Zhu, Mingxia (2016). 'Online Survey on the Revitalization of Zhizhu Temple and Other Heritage Buildings', http://www.diaochapai.com/survey/ f6834acb-9493-40co-bb8f-d8c595825cbd.

Zou Xiao Dang [The Record for Reimbursement] (1756). Entry from June $175^{6}$ (Lunar calendar, the twenty-first year of the Qianlong Emperor's reign), First National Archive of China.

\section{About the author}

Lui Tam, PhD candidate, Sustainable Conservation of Timber Architectural Heritage in East Asia, Welsh School of Architecture, Cardiff University, United Kingdom 


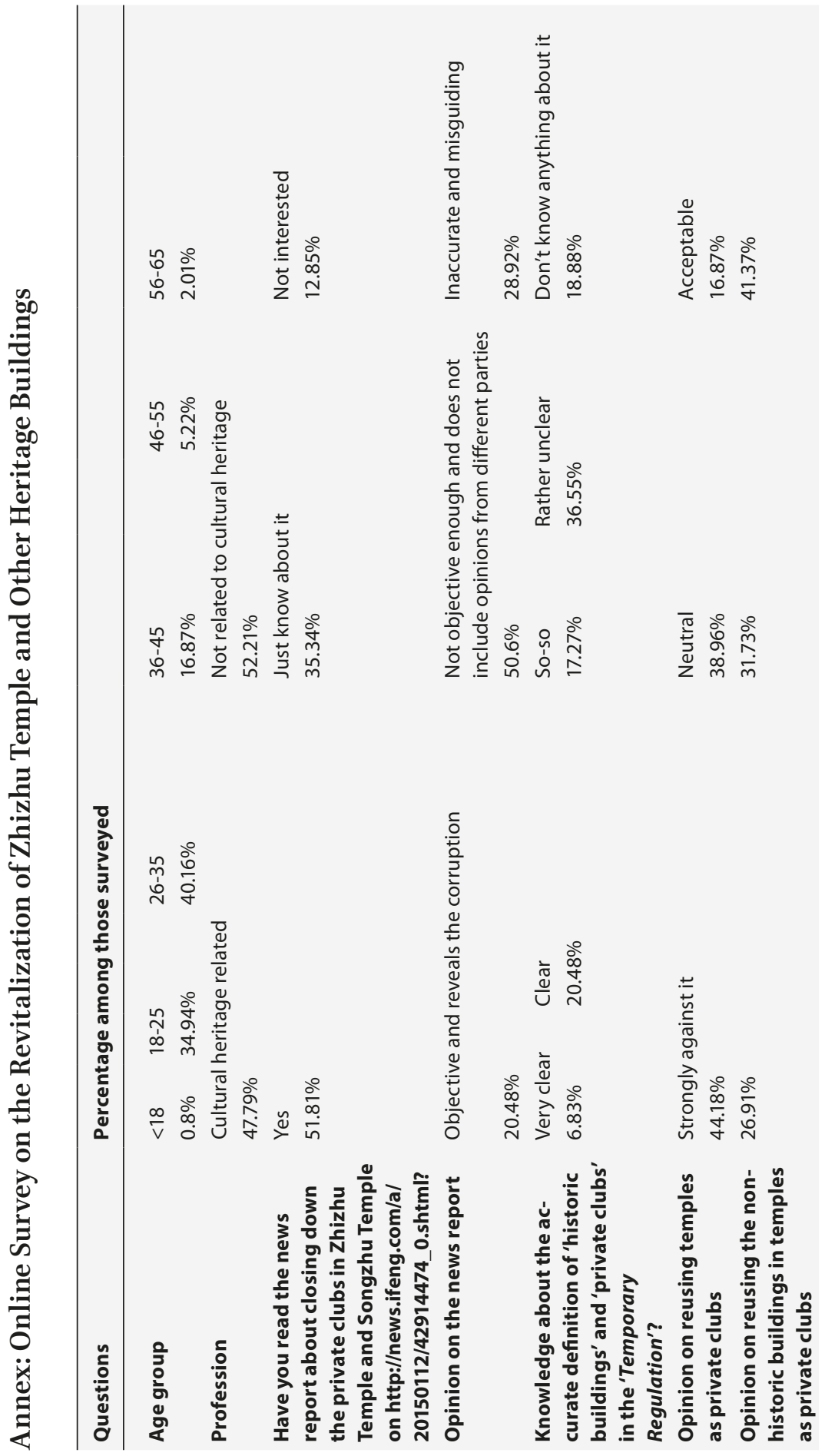




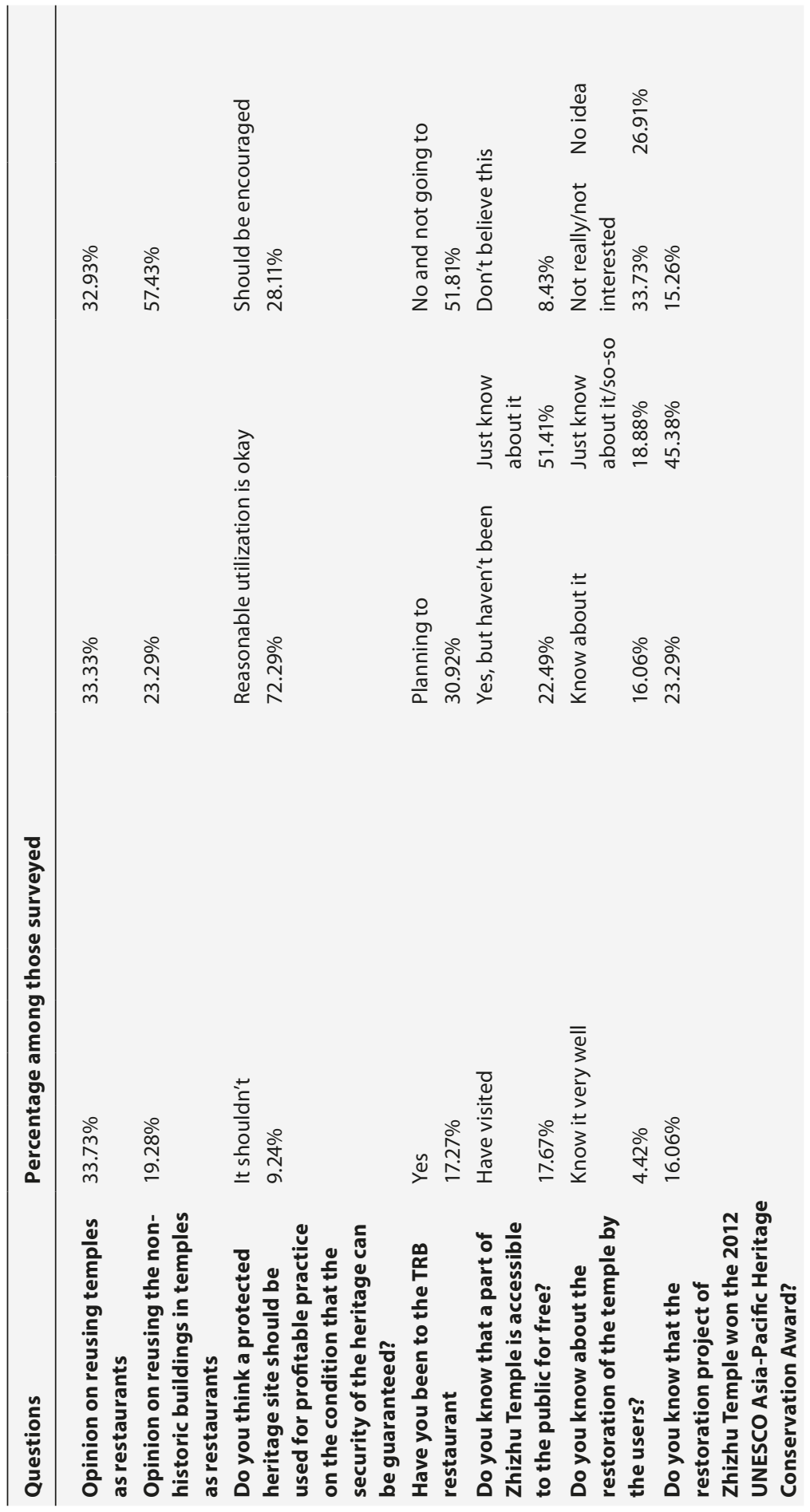




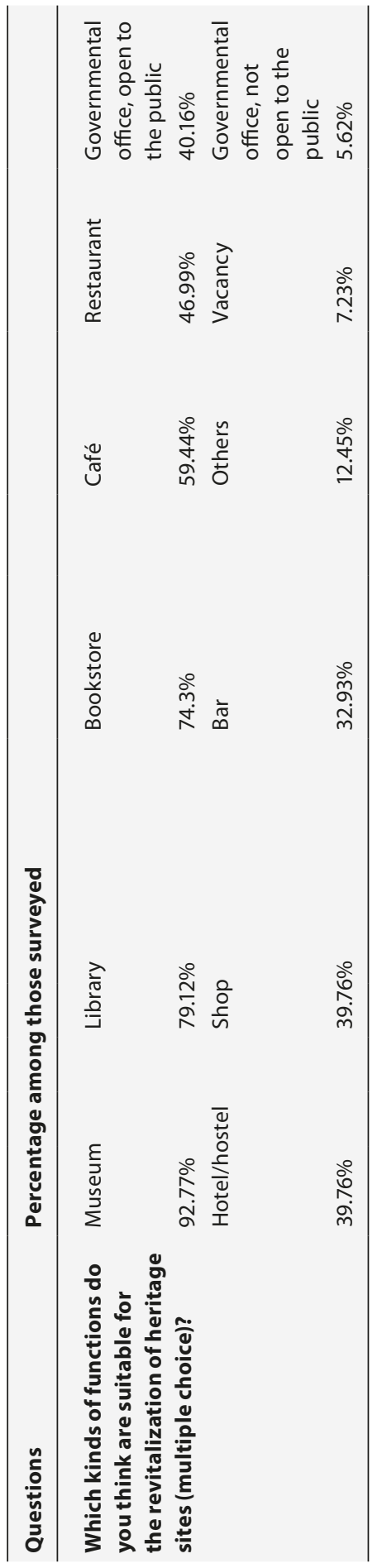

